Thompson anunció que el gobierno buscará la promulgación de nuevas leyes para establecer claramente la autoridad que tiene la FDA para exigir a los fabricantes de productos farmacéuticos la realización de estudios clínicos apropiados para el uso pediátrico de nuevos medicamentos y sustancias biológicas. Afirmó que se buscaría la concesión de autoridad legislativa, por ser una medida más rápida y decisiva que las apelaciones por medio del sistema judicial. La FDA ya ha reafirmado su derecho a exigir esas pruebas, pero el Tribunal de Distrito de los Estados Unidos con jurisdicción en el Distrito de Columbia falló en contra de ese organismo en octubre pasado.

\section{DECISIONES DIVERSAS}

\section{La FDA propone normas de rotulación y fabricación para todos los suplementos alimentarios (Estados Unidos)}

La Administración de Alimentos y Medicamentos (FDA) de los Estados Unidos de América ha tomado medidas que permitirán a los consumidores comprar suplementos alimentarios rotulados con exactitud y sin adulterar, para lo que ha propuesto un nuevo reglamento que exigirá la observancia de las buenas prácticas de fabricación vigentes en el proceso de elaboración, envase y almacenamiento. La reglamentación propuesta establecería, por primera vez, normas para garantizar que los suplementos e ingredientes alimentarios no estén adulterados con contaminantes ni impurezas y se rotulen con exactitud para indicar el principio activo y otros ingredientes del producto.

La reglamentación propuesta comprende los requisitos para el diseño y construcción de las instalaciones, el establecimiento de procedimientos de control de calidad y la realización de pruebas a los ingredientes y suplementos alimentarios fabricados. También incluye los requisitos para mantener los registros y atender las quejas de los consumidores relacionadas con las buenas prácticas de fabricación vigentes.
Los análisis de suplementos alimentarios realizados por un laboratorio del sector privado recientemente indican que un considerable número de los suplementos alimentarios analizados podrían no tener la cantidad de ingredientes que se esperaría encontrar según la información de su etiqueta.

Según la propuesta para la observancia de las buenas prácticas de fabricación vigentes, se exigiría a los fabricantes que evaluaran la identidad, pureza, calidad, potencia y composición de sus ingredientes y suplementos alimentarios.

Esta propuesta abarca toda clase de suplementos alimentarios. Sin embargo, para reducir posibles problemas en la producción de esos suplementos por pequeñas empresas, la FDA ha propuesto la introducción gradual de una reglamentación definitiva para las pequeñas empresas en un período de tres años. La propuesta comprende normas flexibles que puedan evolucionar con los adelantos científicos logrados en campos como la validación de pruebas de identidad, pureza, calidad, potencia y composición de los ingredientes alimentarios.

\section{La FDA autoriza la venta de Prozac ${ }^{\circledR}$ de uso pediátrico para tratar la depresión y el trastorno obsesivo- compulsivo (Estados Unidos)}

La Administración de Alimentos y Medicamentos (FDA) de los Estados Unidos de América ha autorizado nuevas formas de empleo del antidepresivo Prozac ${ }^{\circledR}$ (fluoxetina) para tratar la depresión (trastorno depresivo mayor) y el trastorno obsesivo-compulsivo en niños y adolescentes de 7 a 17 años. Esta es la primera autorización de uno de los tipos de antidepresivos más nuevos (inhibidores selectivos de la recaptación de la serotonina) para tratar la depresión en esa población.

La autorización del uso de Prozac para tratar a niños y adolescentes se basó en dos estudios clínicos controlados con placebo, realizados con pacientes ambulatorios con depresión, cuyo diagnóstico correspondió a los criterios de clasificación habituales (según el Manual de Diagnóstico y Estadística de la Asociación de Psiquiatría de los Estados Unidos). Los síntomas de depresión comprenden abatimiento emocional generalizado, introversión y desasosiego que suele alterar el funcionamiento diario e incluye por lo menos cinco de los nueve síntomas siguientes: depresión del estado de ánimo, pérdida de interés en las actividades habituales, marcado cambio de peso y del apetito, insomnio o hipersomnio (sueño anormalmente excesivo), agitación psicomotora o retraso del desarrollo psicomotor, aumento de la fatiga, sentimientos de culpa o falta de autoestima, raciocinio lento o concentración deficiente, e intento o idea de suicidio.

Los estudios del tratamiento de la depresión mostraron que Prozac tuvo un efecto significativamente superior al placebo en la escala (modificada) de clasificación de la depresión en la infancia.

En niños de 7 a 13 años y en adolescentes de 13 a 18 años con trastorno obsesivo-compulsivo, los resultados con Prozac fueron también significativamente superiores que con el placebo, según la escala pediátrica de medición del trastorno obsesivo de Yale-Brown. Ese trastorno se caracteriza por ideas, pensamientos, impulsos o imágenes (obsesiones) recurrentes y persistentes que son repetitivos y determinados, y por patrones de comportamiento intencional (compulsiones) reconocidos por la persona, uno de sus padres o su tutor como excesivos o irrazonables.

Los efectos secundarios más frecuentes del uso de Prozac en los niños y adolescentes fueron similares a los experimentados por los adultos e incluyeron náuseas, cansancio, nerviosismo, mareo y dificultad para concentrarse. En un estudio clínico con niños y adolescentes de 8 a 17 años, después de 19 semanas de tratamiento con fluoxetina, los pacientes registraron, como promedio, cerca de $1,1 \mathrm{~cm}$ menos de estatura y alrededor de $1 \mathrm{~kg}$ menos de peso en comparación con sus homólogos tratados con placebo. Se desconoce la importancia clínica de esta observación en el crecimiento a largo plazo. Los Laboratorios Lilly han 
accedido a realizar un estudio de farmacovigilancia de fase 4 para evaluar más a fondo cualquier efecto potencial de la fluoxetina en el crecimiento de los niños a largo plazo.

\section{Comité asesor de la FDA discute medidas para la posible reanudación de estudios de terapia génica recientemente suspendidos (Estados Unidos)}

El Comité Asesor en Modificadores de la Respuesta Biológica, de la Administración de Alimentos y Medicamentos (FDA) de los Estados Unidos de América, se reunió para discutir varias medidas que podrían permitir la realización - con la debida protecciónde varios ensayos clínicos de terapia génica relacionados con el uso de retrovirus para incorporar nuevos genes a los hemocitoblastos (células germinales) para el tratamiento de enfermedades potencialmente mortales. Esta reunión es uno de los pasos del proceso esbozado por dicho organismo en enero pasado para ofrecer más seguridad a los participantes de esos estudios y, al mismo tiempo, apoyar la introducción de nuevos tratamientos.

Estos estudios se suspendieron el 14 de enero de 2003 después de recibir un informe de que un segundo niño participante de un estudio clínico en Francia había desarrollado leucemia, quizá como resultado de la genoterapia, por lo demás eficaz para una afección generalmente mortal, a saber, el síndrome de inmunodeficiencia combinada grave ligado al cromosoma $\mathrm{X}$ (conocido también como el síndrome del bebé burbuja). Si bien la FDA cree actualmente que los dos casos de leucemia notificados en ese estudio clínico pudieron ser causados por la genoterapia, un examen aún en marcha de los efectos adversos notificados en todos los estudios realizados hasta ahora en los Estados Unidos de América con vectores retrovíricos similares no ha encontrado pruebas de leucemia presuntamente atribuible a la genoterapia.

Además, la FDA sigue considerando los riesgos potenciales de cualquier tratamiento experimental dentro del marco de sus posibles beneficios. En el caso de los estudios de niños con inmunodeficiencia combinada grave ligada al cromosoma $X$ y de muchos otros estudios de genoterapia, la enfermedad tratada puede ser devastadora y mortal, y para algunos pacientes no hay otra opción.

\section{La FDA autoriza el uso de Clozaril para reducir el riesgo de comportamiento suicida en pacientes con esquizofrenia o trastorno esquizoafectivo (Estados Unidos)}

La Administración de Alimentos y Medicamentos (FDA) de los Estados Unidos de América ha autorizado un nuevo uso del antipsicótico Clozaril ${ }^{\circledR}$ (clozapina) para reducir el riesgo de comportamiento suicida recurrente en pacientes con esquizofrenia o trastorno esquizoafectivo. Clozaril fue autorizado en 1989 para el tratamiento de la esquizofrenia en pacientes que no responden a otros tratamientos disponibles.

La esquizofrenia, un trastorno mental que afecta a alrededor de 1 de 100 personas, suele comenzar en la juventud. Alrededor de 20 a $40 \%$ de los pacientes con esquizofrenia y trastorno esquizoafectivo tratan de suicidarse. El comportamiento suicida se refiere a determinados actos de un paciente que lo ponen en riesgo de morir.

Los pacientes que pueden beneficiarse del tratamiento con Clozaril son los presuntamente expuestos a un riesgo permanente de presentar comportamiento suicida recurrente, según sus antecedentes de intento de suicidio, hospitalización o ideación (pensamientos) suicida con alucinaciones o sin ellas.

La eficacia de Clozaril para reducir el riesgo de comportamiento suicida recurrente se demostró durante un período de tratamiento de dos años en el estudio internacional de prevención del suicidio (InterSePT). En este estudio, con 980 pacientes, se comparó la clozapina con la olanzapina $\left(\right.$ Zyprexa $\left.^{\circledR}\right)$. Se recomienda continuar por lo menos por dos años el tratamiento con Clozaril para reducir el riesgo de comportamiento suicida recurrente. La FDA informó que la mayoría de los pacientes en los grupos del estudio tratados con Clozaril y olanzapina recibieron otros tratamientos para reducir el riesgo de suicidio, incluidos los antidepresivos y otros medicamentos, hospitalización y psicoterapia. Se desconoce el aporte de esas medidas complementarias.

Debido a que los pacientes que toman Clozaril están expuestos al riesgo de padecer agranulocitosis, un trastorno hemático potencialmente mortal, deben someterse a análisis de sangre con frecuencia. Esos análisis son necesarios para detectar ese trastorno hemático en sus etapas iniciales $\mathrm{y}$, si es necesario, que el paciente pueda suspender el medicamento de inmediato. Las convulsiones son otro efecto secundario grave frecuentemente observado.

El número anual de suicidios por esquizofrenia en los Estados Unidos se estima en cerca de 3600 . El costo estimado promedio de un intento de suicidio puede llegar en ese país a US\$ 33000 , principalmente debido a los costos de hospitalización.

\section{Gleevec $^{\circledR}$ autorizado como tratamiento de primera línea para la leucemia mieloide crónica (Estados Unidos)}

La Administración de Alimentos y Medicamentos (FDA) de los Estados Unidos de América anunció en diciembre pasado la autorización de Gleevec ${ }^{\circledR}$ (mesilato de imatinib) para el tratamiento de primera línea de los pacientes con leucemia mieloide crónica, una forma de cáncer poco frecuente pero potencialmente mortal, que afecta a unas 40000 personas en los EUA.

La venta de Gleevec se autorizó por primera vez en mayo de 2001 para el tratamiento de estadios avanzados de leucemia mieloide crónica según el procedimiento de autorización acelerada de la FDA. El medicamento también se indicó como tratamiento de segunda línea para los pacientes en fase crónica después del fracaso del tratamiento con interferón alfa. En ese entonces se nece- 
sitaban más estudios para determinar si ese producto reportaba un verdadero beneficio clínico - como la prolongación de la supervivencia- y para evaluar sus efectos al emplearlo en el tratamiento de la enfermedad en su estadio inicial.

La leucemia mieloide crónica ocurre por traslocación recíproca entre dos cromosomas (9 y 22), formando el llamado "cromosoma de Filadelfia". Esta traslocación desencadena la activación constante de una enzima que estimula la proliferación leucocitaria. Como resultado, se forman concentraciones potencialmente mortales de leucocitos maduros e inmaduros en la médula ósea y la sangre.

Gleevec, un inhibidor específico de la enzima producida por la translocación, bloquea la rápida proliferación de los leucocitos. La autorización se basó en un estudio clínico con 1106 pacientes con leucemia mieloide crónica recién diagnosticada (fase crónica). Se trató a 553 pacientes con Gleevec y a los otros 553 se les administró el tratamiento normal para la leucemia mieloide crónica con interferón alfa y citarabina. Después de 1 año, los pacientes tratados con Gleevec tuvieron menos células cancerosas en la sangre y la médula ósea, y también se redujo la progresión de la enfermedad. Puesto que los pacientes con leucemia mieloide crónica suelen vivir hasta 10 años con la enfermedad, el período de seguimiento de 14 meses (mediana) debe considerarse demasiado breve para poder medir los beneficios clínicos a largo plazo, como la prolongación de la sobrevida.

Hoy en día, Gleevec está autorizado para el tratamiento de pacientes en los tres estadios de leucemia mieloide crónica, a saber, crisis mieloblástica, fase acelerada y fase crónica, ya sea antes o después de la administración de otro tratamiento. La única cura conocida para la leucemia mieloide crónica es el trasplante de hemocitoblastos (médula ósea).

Los efectos secundarios más frecuentemente informados asociados al uso de Gleevec son náuseas, vómitos, edemas (retención de líquidos), espasmos musculares, cansancio, erupción cutánea y cefalea.
Gleevec se ha incluido en la lista de medicamentos huérfanos, destinados a tratar enfermedades poco frecuentes, es decir, trastornos que afectan a menos de 200000 personas en los EUA, por lo que no despierta el interés comercial de ningún laboratorio. La Ley sobre Medicamentos Huérfanos concede un período de 7 años de exclusividad de venta al primer patrocinador que obtenga la autorización de comercialización de un determinado medicamento de esa clase.

\section{ENMIENDAS A LA ROTULACIÓN/ CAMBIOS DE FORMULACIÓN}

\section{La FDA hace una advertencia de riesgos para la salud en las enmiendas a la rotulación de los productos de lindano (Estados Unidos)}

El 28 de marzo de 2003, la Administración de Alimentos y Medicamentos (FDA) de los Estados Unidos de América hizo una advertencia de riesgos para la salud pública relacionada con el uso de formulaciones tópicas de lociones y champús de lindano para el tratamiento de la sarna y los piojos. Esta nota anuncia importantes enmiendas para actualizar la rotulación de esos productos, entre ellas la inclusión de nuevas advertencias y la adición de una guía del medicamento que debe ser distribuida directamente a los pacientes.

La rotulación de los productos de lindano ha sido enmendada de manera que incluya una advertencia resaltada dentro de un marco que destaque las cuestiones de seguridad más importantes relacionadas con el uso de estos productos. Esa advertencia contiene la información necesaria para que los profesionales sanitarios y los pacientes conozcan los posibles riesgos del uso apropiado e indebido del lindano.

La advertencia subraya que los productos de lindano se han venido indicando y siguen indicándose como tratamiento de segunda línea para combatir la sarna y los piojos. Si bien la FDA cree que los beneficios del lin- dano sobrepasan los riesgos cuando se usa de la manera indicada, en vista de su neurotoxicidad potencial, los pacientes solo deben tratarse con estos productos si no pueden tolerar otros o si han fracasado otros tratamientos autorizados.

La nueva advertencia enmarcada indica también que la loción y el champú de lindano deben usarse con cuidado en pacientes que pesen menos de $50 \mathrm{~kg}$. Estos productos no se recomiendan para uso en lactantes y están contraindicados para los prematuros. Estas advertencias se basan en informes enviados al sistema de notificación voluntaria de la FDA que indican que aproximadamente la mitad de los efectos adversos notificados ocurrieron en pacientes pediátricos.

Se estima que en los EUA se expiden hasta 1 millón de recetas cada año para tratar nuevos casos de infestación de piojos y sarna, sobre todo en niños en edad escolar. Debido a que el lindano se absorbe por la piel y los niños más pequeños tienen más superficie cutánea por kilogramo de peso que los adultos, la cantidad absorbida puede dar como resultado mayores concentraciones sanguíneas de lindano en los niños que en los adultos. Los estudios realizados con animales de laboratorio han demostrado que los animales pequeños son más vulnerables a los efectos neurológicos del lindano.

\section{Toman medidas para reducir los riesgos potenciales de los suplementos nutricionales que contienen efedra (Estados Unidos)}

El 28 de febrero de 2003, el Departamento de Salud y Servicios Sociales de los Estados Unidos de América anunció un conjunto de medidas de protección de la población estadounidense contra los riesgos potencialmente graves de los suplementos nutricionales que contienen efedra.

Los resultados de un estudio encomendado a la Rand Corporation por los Institutos Nacionales de Salud (NIH) y otros estudios recientes han permitido comprobar que la efedra puede acarrear graves riesgos para la 